\title{
Memorias de una joven obrera: Actitudes sociales, catolicismo y poderes locales franquistas en una comunidad rural (Béjar, 1939-1960)
}

SARA Martín GutiérReZ

PALABRAS CLAVE: Acción Católica, franquismo, actitudes sociales, posguerra española.

CÓDIGOS JEL: E2, E24, E26, N01, N94.

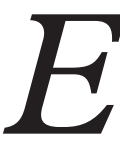

ste artículo aborda, a partir de la historia de vida de una trabajadora bejarana, Lucía García Hernández, el retrato de la cotidianeidad de posguerra en una comunidad rural salmantina. A través de la interpretación de esta fuente $y$ de la reconstrucción de los acontecimientos históricos que sucedieron durante los años cuarenta y cincuenta en Béjar, se pretende dar muestra de cómo los poderes locales del franquismo y de la Iglesia católica trataron de imponer una representación única de la identidad nacional. Frente al poder autoritario se examinan desde el enfoque de la history from below las diferentes actitudes y comportamientos sociales de las trabajadoras textiles de Béjar y también la movilización de las mujeres católicas en relación a estas, especialmente sobre la cuestión de la moralidad femenina. Para ello, se pone especial énfasis en el estudio de las experiencias comunes articuladas desde las nociones de género, clase, raza y edad. Finalmente, se examinan algunas de las sociabilidades de la Acción Católica Obrera, una suerte de espacios o zonas grises donde los trabajadores y las trabajadoras vivieron una religiosidad diferencial y pudieron compartir algunas de las experiencias que vivían no solo en las fábricas donde trabajaban, sino también las dificultades de muchas familias ante la posguerra. 


\title{
A Young Female Worker Memories: Social Attitudes, Catholicism and Franco's Local Powers in a Rural Community (Béjar, 1939-1960)
}

\section{KEYWORDS: Catholic Action, Francoism, social performance, Spanish post-war.}

\author{
JEL CODES: E2, E24, E26, N01, N94.
}

his article shows through a female worker life history in Béjar, named Lucia
García Hernández, an ordinariness story during post-war time in a rural
community located in Salamanca. Through this oral source interpretation and also through the historical events that happenned in the fourties and in the fifties in Béjar, this articles intends to explore how local authorities from Francoism and Catholic church imposed the representations of national identity. Straight ahead the dictatorship power, this paper examines from the history from below approach the different attitudes and social behaviours from the textile female workers in Béjar and also the Catholic female mobilization concerning to these ones, specially on morality issue. For that purpose, special emphasis is placed upon common experiences from gender, class, race and age notions. Finally, this article examines some of the sociabilities from the Catholic Workers Action, "grey places" where female and male labor force experienced a different way of religiousness and shared ordinariness happenings related to labour factories and family difficulties during the Spanish post-war.

Recepción: 2020-07-13 - Revisión: 2021-03-14 - Aceptación: 2021-03-15

Sara Martín Gutiérrez [orcid.org/0000-0002-2064-8301] es doctora en Historia Contemporánea por la Universidad Complutense de Madrid con mención europea por la Università degli Studi di Firenze (2017). Actualmente desarrolla sus investigaciones postdoctorales en el Consejo Nacional de Investigaciones Científicas y Técnicas (CONICET) en Argentina. Dirección para correspondencia: c/ Puán, 480, 4. ${ }^{\circ}$ piso, Facultad de Filosofía y Letras, Universidad de Buenos Aires, Ciudad Autónoma de Buenos Aires (Argentina). C. e.: sarmar02@ucm.es 


\section{INTRODUCCIÓN}

A mediados de la década de los cuarenta el movimiento de Mujeres de la Acción Católica intensificaba su movilización política en medio de un contexto atravesado por la represión y el hambre generado por la instrumentalización de la política autárquica del régimen franquista. A través de la interpretación de una historia de vida perteneciente a la colección Biografías obreras del Archivo de Historia del Trabajo-Fundación $1^{\circ}$ de Mayo de Comisiones Obreras (CC. OO.), este artículo indaga en las actitudes sociales de las identidades trabajadoras rurales que pervivieron al interior de la Acción Católica Española (ACE) en el contexto de su fuerte resignificación durante los primeros años de la dictadura franquista (Llona, 2012a).

Lucía García Hernández nació durante la Segunda República en Béjar, localidad en la que vivió hasta su traslado a Madrid en 1971. Trabajadora de la industria textil de la comarca, fue conocida entre los sectores femeninos del catolicismo social por su papel como vocera entre las jóvenes obreras que se empleaban en las fábricas cercanas al pueblo. Participó en el movimiento jocista y también en la Hermandad Obrera de Acción Católica Femenina (HOACF), aunque durante su juventud mantuvo actitudes de tensión, resistencia y negociación con las dirigentes de la Acción Católica en Béjar, donde se pusieron de manifiesto las diferencias de clase entre mujeres, así como el clientelismo que pervivía entonces en la comarca.

La interpretación del testimonio de Lucía García Hernández, entrevistada en 2007 por José Babiano ${ }^{1}$, permite hilvanar el estudio de las identidades trabajadoras femeninas en los espacios físico y simbólico de una pequeña comunidad rural de la región salmantina, Béjar, y reflexionar acerca de los comportamientos sociales de las mujeres frente a los mecanismos de disciplinamiento social de los poderes locales, tanto políticos como religiosos.

Las fuentes orales, y más concretamente, las posibilidades de interpretación que posibilitan las historias de vida permiten arrojar luz sobre dimensiones que de otro modo permanecerían en la sombra (Llona, 2012b: 22; Passerini, 2010). Los relatos de la memoria se encuentran fuertemente permeados por la compostura o autocensura que guardan los sujetos respecto de la sociedad de su tiempo en un intento por adaptar sus recuerdos alterizantes a los códigos de «aceptabilidad» de las mayorías sociales (Summerfield,

1. Entrevistas realizadas el 17 y 25 de enero de 2007 en Madrid. Disponible en la Fundación $1^{\circ}$ de Mayo, colección Biografías obreras y militancia sindical en CC. OO., Lucía García Hernández, BIO-062/01, BIO-062/06. 
2004). Recordar es un proceso cargado de significado, tanto para aquellas memorias individuales como para las colectivas. Según Halbwachs (2011), se producen procesos de memorización y formas de generar recuerdos en el interior de cada grupo social que los diferencian de otros a través de los marcos sociales de la memoria, que es el lugar donde situamos las relaciones de parentesco o los diferentes sistemas de clasificación social (género, clase, raza, etnia, religión).

En este trabajo partimos del poder activo que tienen los sujetos en los procesos de conformación de sus identidades individuales, entendiendo que estas se valen a su vez de ciertas representaciones que son empleadas durante este proceso (Chartier, 1992; Rosa, Bellelli \& Bakhurst, 2008). A través de una historia de vida analizamos un contexto autoritario y las representaciones que se difundieron durante los primeros años de la posguerra española. En este relato exploramos cómo la identidad individual se conforma a través de la diferencia (Derrida, 1967), construida antagónicamente como alteridad. Estas identidades diferenciales se encuentran condicionadas por estructuras o formas de clasificación social que se organizan a partir de nociones de género, clase, raza, etnicidad, sexualidad o edad (Briones, 1998; Mintz, 2008) a partir de las reflexiones que se han formulado los últimos años desde las retóricas decoloniales y de género (Lugones, 2008).

El propósito de este artículo es lograr una mayor comprensión acerca de las distintas actitudes sociales (aceptación, negociación, transgresión, resistencias) que las trabajadoras católicas experimentaron respecto de las representaciones, cultura y sistemas de reordenamiento social de la España franquista en un contexto de ruralidad (Cenarro, 2005; Nielfa, 2003; Ortega, 2006). Durante los últimos años, un número importante de investigadores e investigadoras ha comenzado a profundizar en las actitudes sociales de distintos colectivos desde el enfoque de la history from below (Thompson, 1966) con especial énfasis en la naturaleza de las relaciones sociales, los comportamientos de la población local y la transformación de las identidades populares (Hernández Burgos, 2014; Arco et al., 2013). Retomando este amplio campo de estudios sobre la gente corriente que nombraría años más tarde Eric Hobsbawm (1999), se analizan las experiencias cotidianas de una joven trabajadora bejarana en las sociabilidades del catolicismo de posguerra a través de las formas narrativas presentes en la microhistoria (Ginzburg, 1976; Serna \& Pons, 2019).

Con el propósito de profundizar en el conocimiento de la realidad cotidiana de las mujeres trabajadoras en Béjar, esta investigación se nutre de la perspectiva "desde abajo», y pone el foco principal en las voces de determinados agentes sociales (Rodríguez Barreira, 2013). Este enfoque de la historia social y cultural permite realizar un análisis de las clases no privilegiadas o subalternas de la sociedad española de posguerra para entender los 
apoyos de ciertas familias rurales al régimen de Franco, pero también las dificultades que encontraron en su accionar con otros grupos sociales, por ejemplo las clases populares de las comunidades no urbanas.

Estas líneas incorporan el concepto thompsoniano de experiencia. Las formas teóricometodológicas de los marxistas británicos instalaron la conciencia como foco destacado en su profundización sobre el papel de los agentes históricos. Se inauguraba así una tradición vertebrada en el análisis cultural como herramienta para colocar en el centro de la mirada investigadora los lenguajes, discursos y también las culturas «obreras» (Miguel \& Hobsbawm, 2013: 21). De esta forma, esta perspectiva nos permite indagar en las lógicas sociales de ciertas comunidades rurales y también en sus sistemas de creencias, que continuaron vigentes durante la posguerra.

Entendemos experiencia como noción que vincula el ser social con la conciencia, interpretandola desde la crítica posterior realizada por los estudios de género (Llona, 2016). Para Thompson, la experiencia se encontraba relacionada con el tipo de respuestas que otorgan los individuos y también los grupos colectivos a acontecimientos vinculados entre sí, es decir, una manera de comprenderlos, vivirlos y responder ante estos en un momento concreto (Thompson, 1989). Según el historiador, la conciencia no se disocia de la experiencia si bien esta aparece como determinada. El mundo racional es inseparable del campo emocional, de los sentires, ya que esta dimensión psicológica también actúa de catalizador de la movilización o como factor que determina la forma de entender el mundo en el que viven estas identidades. La experiencia permite aproximarse a las prácticas y vivencias de los sujetos históricos, en este caso las comunidades populares de la ruralidad, dentro de múltiples abordajes (Garazi, 2016: 3).

E. P. Thompson presentó la correlación existente entre la conciencia de clase y las experiencias «vividas» por las clases trabajadoras, las formas de vida, la cultura y otras nociones como la emocionalidad o la subjetividad de los sujetos ${ }^{2}$. Sin embargo, siguiendo a Joan W. Scott sostenemos que sin analizar las experiencias desde la perspectiva de género se continúan reproduciendo las desigualdades históricas a las cuales los historiadores sociales trataron de poner fin a partir de la década de los sesenta (Scott, 1989: 96).

Por otro lado, nos inspira la perspectiva teórica del antropólogo James Scott (1985) en sus análisis acerca de las estrategias de resistencia cotidiana de los colectivos campesinos y cómo estos manifestaron sus propias voces a través de sutiles códigos o actitudes situadas en un amplio abanico entre disconformidad y la insubordinación. Pensamos

2. Scott alertaría de que el concepto de experiencia poseía una dimensión construida y sexuada. 
como Scott que uno de los factores que incidió en esta movilización desde las periferias fue la existencia de redes de apoyo mutuo desde las cuales las identidades "campesinas» manifestaron una pluralidad de actitudes de «baja intensidad» frente a la dominación de la identidad «nacional» (Roca, 2017). Esta identidad nacional sería la columna vertebral de la cultura de la victoria franquista. La representación de hispanidad del imaginario patriótico se articularía a partir de la dimensión de raza como sistema de inclusión o exclusión de la población local de esta identidad nacional (Marcilhacy, 2014). Por todo ello, nos interesa comprender si las identidades trabajadoras del área rural salmantina fueron incluidas o excluidas de esta construcción del franquismo.

Por otro lado, nos interesa trascender la visión dicotómica de la realidad histórica para entender la importancia que cobran los grises en el relato de la posguerra franquista. Esto nos posibilita encontrar experiencias o aconteceres en los cuales ciertas identidades pueden servirse de distintas estrategias para manifestar actitudes como la colaboración o la negociación, en especial en comunidades rurales pequeñas donde existe una proximidad mayor entre sus habitantes. También nos ayuda a inquirir en las supuestas identificaciones de las identidades rurales trabajadoras con relación a los discursos y representaciones del régimen de Franco. De la misma forma, vamos a encontrar distintas vías de oposición a los poderes oficiales del franquismo, en especial cuando estos chocan con los propios intereses, valores, cultura y experiencias de estas identidades trabajadoras.

Cuando indagamos en las caras de la "cotidianeidad", encontramos distintas actitudes situadas en un amplio espectro que va desde aquellas subjetividades que fueron fidedignas respecto de las normativas legales de la dictadura, y también de aquellas identidades cuyas prácticas cotidianas no siempre fueron coincidentes con los dictados oficiales franquistas (Gonzalbo, 2006: 19). Esta perspectiva que nos acerca a la cotidianeidad rural nos desvela una mayor complejidad de los procesos históricos en tanto descubrimos las zonas grises o los matices presentes en las actitudes de consenso, transgresión o resistencia de los distintos agentes sociales del mundo rural. Al mismo tiempo nos permite profundizar en la existencia de otras formas de relación social sustentadas en códigos como la reciprocidad limitada o la existencia de determinadas negociaciones aplicadas a las formas de vida rurales (Hernández Burgos, 2019: 312).

En este artículo se prioriza narrar el acontecer del pasado desde esta pluralidad para comprender de qué forma las experiencias comunes pueden transformar los comportamientos contestatarios y la movilización de estos en tiempos del autoritarismo. A partir de todas estas aportaciones teóricas reflexionamos acerca de la forma histórica en la cual sentían, pensaban o se movilizaban las mujeres trabajadoras de una población rural y la actitud de estas respecto de las instituciones que ostentaron los poderes políticos y sim- 
bólicos en Béjar: las autoridades franquistas, el empresariado textil y también los agentes sociales de la Iglesia católica.

La historia de la vida cotidiana nos permite abrir una ventana a «lo mundano». Más allá, habilita una óptica integradora que ensambla las vivencias de intimidad de las identidades con los aconteceres de su mundo externo: sus experiencias en espacios comunes como el trabajo fabril, las calles del pueblo, las plazas y parroquias... Así, este trabajo pretende trascender los «relatos heroicos» del movimiento obrero urbano. Aquí nos interesa explorar los caminos que encontraron mujeres como Lucía García Hernández para poder actuar desde las periferias rurales, en este caso, como portavoces de las identidades populares de su comunidad.

\section{ENTRE COSTURAS: EXPERIENCIAS OBRERAS DE UNA COMUNIDAD RURAL EN LA POSGUERRA}

Lucía García Hernández nació en la primavera de 1934 al calor de la experiencia republicana en la localidad salmantina de Béjar. De padre anarquista, de profesión fontanero, y madre que ejercía como ama de casa, era la segunda de cuatro hermanos. De su padre recordaba su fuerte impronta anticlerical ${ }^{3}$; de su madre, que era algo religiosa, aunque no frecuentaba la iglesia, sino a un "nazareno con fama de milagroso». Ambos progenitores podían leer y escribir, y su padre guardó especial cuidado en la educación de sus hijos e hija, aunque priorizando que fueran los varones quienes completasen el título de bachiller. Para su hija, según rememoraba Lucía, esperaba que contrajese matrimonio e hiciera «vida de casada».

Tras el fallecimiento de su madre cuando contaba ocho años de edad, Lucía se quedó a cargo de sus tres hermanos varones, todos ellos menores de edad. Tiempo después su padre contrajo segundas nupcias con una mujer del pueblo, analfabeta, con el propósito de que esta pudiera encargarse del cuidado de sus hijos e hija, y de las tareas domésticas de la casa. A pesar de que esto pudiera aliviar parcialmente a Lucía de ciertas obligaciones de la cotidianeidad del hogar, este hecho marcaría su primera etapa vital, ya que continuó ausentándose del colegio como tantas otras infancias rurales de la posguerra: "Yo hacia lo que hacían entonces las niñas: lavar, fregar y coser calcetines, las rodilleras

3. De su padre también recuerda su carácter contestatario. Para impedir que sus hijos e hija disfrutasen de los regalos que repartía el Auxilio Social en la festividad de Reyes, un año se deshizo de los juguetes delante de ellos, y les construyó él mismo otros. Sobre el Auxilio Social, véase CENARRo (2013) y sobre la política social del régimen, MOLINERO (2003). 
de mis hermanos...». De su etapa en la escuela, recordaba con cariño el gran aprendizaje que pudo hacer gracias a la dedicación particular de una profesora «de la República» que les daba clases a ella y a uno de sus hermanos a escondidas en su casa.

Desde los once acudía por las tardes a la casa de una zurcidora empleada en la fábrica donde trabajaba su padre para aprender la destreza de los hilos. Su progenitor le había solicitado este favor con la esperanza de que Lucía aprendiera el oficio y pudiera incorporarse al mercado laboral de la industria textil bejarana, para sumar así un segundo jornal que mitigase las carencias económicas del núcleo familiar. La cotidianeidad ameritaba que hijos e hijas de corta edad se incorporasen al mercado de trabajo para aumentar la entrada de dinero. Tras aprender a coser con cierta soltura, Lucía empezó a trabajar a los catorce años en una fábrica textil de su pueblo, donde se empleó primero como repasadora. Después trabajó como zurcidora en distintas fábricas de los alrededores, entre ellas La Estambrera, hasta que años después contrajo matrimonio con un hilandero que conocería en el movimiento de la Juventud Obrera Católica (JOC) (Moreno, 2016). La obrera recordaba cómo a los trabajadores se les solía pagar las horas extra que realizaban en su puesto de trabajo, mientras que a las mujeres se les permitía llevarse la tarea para concluirla en sus casas.

Parte de los recuerdos que repasaba Lucía en su entrevista acontecieron en Béjar durante las décadas de los cuarenta y cincuenta. La represión durante la guerra civil había sido especialmente cruenta respecto de otras zonas de la comarca, en especial cuando en el verano de 1936 los falangistas ocuparon el pueblo. Según Lucía, Béjar había sido durante los años de República "el punto rojo de Salamanca, una provincia conservadora». Esta construcción que pervivía en el imaginario de su infancia, observada desde los ojos de una niña que veía camiones repletos de caras conocidas esperando una condena de muerte, fue también apoyada por la influencia que en ella despertaron el pensamiento y las charlas con su padre.

Béjar en la década de los treinta era el núcleo industrial y con mayor organización obrera de la región. Desde principios del siglo XX se habían sucedido numerosos conflictos textiles. El último motín había ocurrido precisamente el año de nacimiento de Lucía, en 1934, cuando se interrumpieron los encargos de los uniformes del ejército que hasta ese momento se realizaban en las diferentes fábricas bejaranas, un acontecimiento que afectó enormemente no solo a las empresas textiles, sino también las vidas de los obreros y obreras que en estas se empleaban. Una parte importante de aquellos y aquellas que fueron asesinados entonces tras la ocupación falangista se desempeñaban entonces como sastres, hilanderos o tejedores en distintos enclaves fabriles cercanos. 
Dentro de su rutina diaria, Lucía García solía acudir por las tardes a un comedor social de mayores gestionado por una congregación de religiosas. Allí colaboraba con el reparto de raciones de comida todas las tardes tras terminar su jornada en la fábrica. Según su percepción, las monjas solían ser amables en el trato con ella. El hambre había motivado a Lucía a acercarse a los ambientes católicos, pues recibía un bocadillo que ella a su vez guardaba para entregárselo a su hermano pequeño ${ }^{4}$. La portera del asilo, al percatarse de esto, había solicitado a las cocineras que por favor le entregasen dos raciones a la joven. "Me sentía querida, y yo quería ser de eso", recordaría. Lucía evocaba en su testimonio que sentía que en el asilo tenía el afecto -y el refugio- que le había faltado en su casa tras el fallecimiento de su madre, un elemento que pareciera constituirse como pieza clave en cómo asumió de manera positiva la experiencia de la caridad católica ${ }^{5}$. Gracias también al tiempo semanal que dedicaba a las tareas de reparto de las raciones de comida con las monjas, Lucía expresó entonces una aspiración de pertenencia que le habilitaría poco tiempo después un deseo de ser parte de la congregación religiosa. Así, cuando contaba con quince o dieciséis años de edad se marchó a un convento de Plasencia recomendada por las monjas, con el dinero que había podido ahorrar del jornal de la fábrica $^{6}$. Tres días después, tras dar su padre aviso de su partida ante la Guardia Civil, regresó a Béjar ${ }^{7}$.

Poco tiempo después de este episodio, desestimó la idea de tomar los hábitos, cansada de que las religiosas le dieran la orden de entregar la peor ración de comida a Agustina, una mujer de su pueblo que acudía al asilo. Tras ahondar en las razones que motivaban esta exclusión de la comunidad, Lucía se enteró de que aquella mujer de mediana edad

4. «Mi padre cobraba 170 pesetas a la semana y eso se consideraba un gran sueldo. Yo todos los días bajaba a la carnicería y me gastaba 1 peseta para comprar carne para el cocido. Los precios estaban ajustados, pero recuerdo haber pasado mucha hambre. Recuerdo haber pasado por las fuentes de agua para beber y ver si me quitaban el hambre.»

5. Las emociones o la historia de los afectos pueden ayudarnos a comprender algunos fenómenos históricos (BJERG, 2019). Si bien es cierto que las tareas de gestión del cuidado han sido depositadas históricamente sobre las mujeres, este factor de índole emocional o psicológico del relato de Lucía García nos permite profundizar en esta experiencia desde la historia de las emociones. A partir de ella comprendemos entonces mejor cómo este elemento del cuidado hacia otros y otras se conformó a partir de una emoción de falta de alimento, de hambre, pero también de afecto, un aspecto que influyó en la decisión de Lucía García de cuidar y nutrir a otros y a otras.

6. «Yo no había salido del pueblo más que para ir a casa de mi tío. Mi tío me deja en la estación, y yo cojo el billete para Plasencia, como no me lo dan voy a Salamanca, y de ahí a Plasencia. Había ahorrado de las cosas que había cosido. De Plasencia tengo que ir a Medina del Campo, luego Valladolid... llevaba la dirección. La directora de Béjar ya había llamado por teléfono que iba para allí.»

7. «Yo vivía sin afecto de nada ni de nadie. Fue eso lo que a mí me hizo refugiarme en las monjas ya antes de la muerte de mi padre. Yo me quería ir al convento y mi padre horrible que yo quisiera ser monja. Él decía "antes te mato". Fue una lucha. Me impedía que fuera al convento y me escapé.» 
era familiar de rojos. Los discursos del régimen situaron la identidad patriótica y católica al servicio del poder dictatorial, mientras colocaron en la representación de la anti-España a los rojos y a las rojas, los enemigos del franquismo, quienes se oponían a la construcción simbólica y autoritaria de la España franquista. A través de esta estigmatización se excluía de la identidad nacional a los vencidos de la guerra (Hernández Burgos \& Arco, 2011:75).

Lucía García evocaba a través del recuerdo de Agustina, quien comía siempre sola, la tristeza de su rostro, y ponía de manifiesto la situación de las mujeres que tuvieron que acudir a las distintas instituciones de la Iglesia católica como estrategia de supervivencia (Barranquero \& Prieto, 2003). Siguiendo a Mauss, que plantea la alimentación como hecho o fenómeno social, es importante destacar que uno de los hitos que marcaría la vida cotidiana de la posguerra fue la autarquía (Cobo \& Ortega, 2004). Esta política económica fue en realidad utilizada como instrumento de control social, un hecho que a su vez favoreció la intensificación de la labor asistencialista de las instituciones católicas (Arco, 2006).

Con su marido y dos hijos represaliados, asesinados en nombre del nuevo orden, y señalada por sus lazos familiares, la posibilidad de encontrar un empleo en una localidad rural donde resultaba imposible pasar desapercibida era algo inalcanzable. Además, Agustina y su marido regentaban una pescadería, que tras el triunfo franquista pasó a manos de un falangista. La instauración del régimen había traído consigo una fuerte represión que sufrieron no solo quienes apoyaron la República, sino también aquellos vinculados - por lazos familiares-a antiguos sindicalistas, políticos o simpatizantes republicanos. El 9 de febrero de 1939 se había promulgado la Ley de Responsabilidades Políticas, la cual garantizaría la deshumanización de la violencia y de todas las víctimas a partir de entonces (Murillo, 2012: 14; Arco et al., 2013; Rodríguez Barreira, 2008; Cobo \& Ortega, 2005).

Desde una parte de la historiografía se ha utilizado la categorización de represión sexuada (Abad, 2009) para analizar la persecución que experimentaron las mujeres desde una doble perspectiva analizada en clave de género. Así, dichas investigaciones han demostrado que el aparato franquista anuló su identidad política en tanto ciudadanas, y, por otro lado, promovió persecuciones orientadas a atacar ciertas características asociadas a la construcción sociocultural de la feminidad. Este sería el castigo que vivieron por abandonar los espacios históricos articulados para las mujeres, el ámbito de lo íntimo (Peinado, 2018: 340).

Los lazos familiares fueron el pretexto para llevar a cabo una represión sexuada, que castigaba con la exclusión de la comunidad y con el hostigamiento cotidiano ante la sospecha de «simpatizar» con los pensamientos e ideologías políticas de las indentidades mas- 
culinas. Además, parte de las estrategias de control social estuvieron orientadas a la domesticación de los cuerpos femeninos, y en este papel, las instituciones vinculadas a la Iglesia católica jugaron un papel relevante a través de la instrumentalización de la moralidad (Blasco, 2005a).

Las memorias de Lucía García nos recuerdan que también hubo voces que encontraron distintas estrategias en la rutina cotididiana para contestar a los poderes del orden locales. Así, tras acompañar a Agustina en algunas de sus comidas, la trabajadora planteó a las monjas su desacuerdo por el trato que se daba en el asilo a las mujeres que «eran señaladas». Esta discrepancia sería el detonante por el cual Lucía García dió por clausurada su participación en el comedor social y se apartó de los circuitos de la caridad católica. Desde una dimensión subjetiva, sus creencias sobre la justicia/injusticia, pero también sobre las representaciones de la piedad se impusieron paradójicamente al peso de los discursos del control social. En este contexto, la trabajadora se atrevió a manifestar su propia voz de forma directa, y a anteponer sus convicciones a las representaciones oficiales del régimen y de la Iglesia ${ }^{8}$.

Desde su agencia podemos interpretar la pervivencia de comportamientos sociales asociados a la cultura popular, pero intensificados por el sentido de pertenencia a una comunidad rural que se mantuvieron aun en tiempos de la represión. Se trata de actitudes, valores y significados colectivos que atañen las formas de vida, creencias, prácticas y comportamientos concretos (Hernández Burgos \& Arco, 2011: 74). Las identidades van a resignificarse en unión del diálogo entre la cultura y las experiencias, a partir de cómo los sujetos se movilizan o actúan interpelados por las condiciones sociales en las que viven y la forma en que estas son percibidas por ellos. Así, el apoyo mutuo, el cuidado a la vecindad, o la solidaridad, fueron algunos de los códigos que Lucía García había aprehendido en su infancia al observar el sentido de amistad, de pertenencia de su progenitor a ciertas sociabilidades rurales politizadas, y cómo estas a su vez se conformaron como una suerte de orden familiar y de sostén para su padre. Redes que, paradójicamente, también lo alejaban de su propio núcleo familiar ${ }^{9}$. Así, pensamos como Durkheim (1987) que el mantenimiento de cierta acción de rutina, sostenida en la cohesión social o el bien común conlleva al surgimiento de la solidaridad orgánica en las pequeñas comunidades.

8. "Yo se lo planteé a la monja, ¿Por qué hay que echarle lo último?, y me dijo: "Porque es roja”. Mira, le dije, mi padre es rojo, y tendría usted que parecerse a la suela de su zapato, porque se ha pasado ayudando toda la vida al que ha podido. Me fui y no volví. Vinieron a casa a preguntarme y le expliqué lo mismo.»

9. «Mi padre y la panda de mi padre eran todos de izquierdas. [...] Era gente de izquierdas como muy normalita, vivían en familia, mucho sentido de compañerismo... se querían mucho.» 


\section{FOLCLORE Y RELIGIÓN: LAS TRABAJADORAS SE APROPIAN DE LOS LUGARES DE ESPARCIMIENTO}

La rutina cotidiana en el pueblo permitía a las jóvenes trabajadoras de la industria textil combinar momentos para el juego -adolescente- con las largas jornadas laborales. Así, Lucía García junto con algunas de sus compañeras de la fábrica quedaban para entrenar a las seis de la mañana al baloncesto, antes de entrar a trabajar. Tras terminar la jornada, y durante algunos tiempos libres en el fin de semana, se volvían a reunir para ensayar algunos de los bailes regionales, una de las actividades de socialización que fueron dotadas de nuevos significados por los agentes de la dictadura de Franco. La diferencia regional se folclorizó. Aquellas costumbres, usos ancestrales, danzas y cantos tan propios de las identidades locales comenzaron a hacerse visibles como intrumento político de cohesión social y como vehículo para reivindicar una pertenencia de índole nacional (Asunción, 2017).

En 1938, la Sección Femenina de Falange había impulsado la Regiduría de Cultura en un intento de controlar las instituciones y centros dedicados al folclore en España. El propósito no era otro sino colocar la cultura popular al servicio de las élites que gobernaban y apoyaban la dictadura de Franco. En cualquier caso, muchas de las jóvenes bejaranas se servían de este danzar en comunidad durante sus momentos de esparcimiento, concediéndole un uso propio, desprovisto del simbolismo para el disciplinamiento. Esto sucedía especialmente cuando se reunían para ensayar estos bailes al margen de las instituciones de la Sección Femenina o en lugares que se encontraban fuera de su tutela y vigilancia.

La diversión propia de las infancias, pues las trabajadoras apenas contaban con trece o catorce años de edad, se entrelazaba así con la dureza de la vida laboral: largas jornadas de trabajo, bajos salarios o casos conocidos de compañeras que eran abusadas por los superiores o encargados, algunos de los cuales fueron denunciados por Lucía García ante el dueño de la fábrica donde estaba empleada. De él Lucía recordaba que era «beato»y solía comulgar antes de acudir a su despacho. A comienzos de los años cincuenta, en Béjar se organizó una asociación llamada Santa Justa y Rufina dirigida a las jóvenes obreras. Había sido promovida por «un cura fascista», don Ricardo, y pronto Lucía y sus amistades comenzaron a participar en ella: «Nosotras nos metemos allí. [...] Éramos Santa Justa y Rufina. Llegan las señoras de Acción Católica a hablar a las jóvenes obreras. Vienen a ese centro a hablarnos, de que teníamos que ser puras, castas, no ir al baile, no ir sin medias, sin mangas... me resultó indignante», explicaría esta obrera textil. Lucía entendía entonces que las experiencias de vida de sus compañeras obreras nada tenían que ver con los arquetipos de feminidad de la Acción Católica, fuertemente atados a la mo- 
ral ceñida sobre los cuerpos de las mujeres. Cuerpos que, por otro lado, podían ser violentados por los mismos representantes de ese orden católico y patriótico que vigilaban las fábricas.

Retiros espirituales, representación de obras teatrales, talleres de oficio, costura o peregrinaciones, clases de alfabetización, reparto de alimentos y de distintos utensilios para el hogar fueron algunas de las estrategias que emplearon las mujeres de las clases acomodadas de la ruralidad bejarana para acercarse a las trabajadoras (Blasco, 2005b; Hernández Burgos, 2013; Moreno, 2011). El fin pareciera ser la difusión de ciertos códigos de la moralidad orientados al mantenimiento de las buenas costumbres. A través de la movilización proselitista de las católicas, estas buscaban que las mujeres preservasen su «honorabilidad». En realidad sobre ellas recaía la matriz de una representación extensiva del honor familiar patriarcal. El control sobre los cuerpos de las mujeres, sobre su sexualidad, si bien encontraba ahora un amparo legislativo en las políticas de género del régimen, lo cierto es que formaba parte de uno de los ejes de la Acción Católica desplegado en las décadas anteriores ${ }^{10}$.

Si bien muchas trabajadoras sintieron, asumieron o fingieron esta moralidad conservadora, hubo otras jóvenes, como Lucía, para quienes la vida cotidiana traía consigo otros problemas más importantes que resolver. Cuestiones tan básicas como la alimentación, la materialidad de la vida o los problemas en el trabajo se antepusieron a las preocupaciones de las señoras de la Acción Católica (Martín Gutiérrez, 2020). Las experiencias de vida entre las mujeres «ricas» y aquellas pertenecientes a los sectores populares distaban mucho de parecerse aún en una pequeña comunidad como Béjar. Mientras la Acción Católica difundió representaciones de género orientadas a cohesionar a todas las mujeres bajo un único arquetipo de feminidad ligado a la domesticidad del hogar y al papel de estas como madres y esposas (Arce, 2016), trabajadoras como Lucía García reivindicaron una identidad de clase que rompía precisamente con este modelo.

Poco tiempo después, el grupo de jóvenes trabajadoras que se reunía a bailar las danzas regionales fue interceptado por un consiliario de la Juventud Obrera Católica Femenina (JOCF). El sacerdote había llegado recientemente a Béjar con el cometido de expandir el movimiento jocista en la región. Durante la posguerra, la Acción Católica había intensificado su proselitismo a través de peregrinaciones, procesiones y catequesis dirigidas a los sectores trabajadores (López García, 1995: 31). Sus actores retomaban una

10. Esta moralidad y control de los cuerpos de las mujeres era compartido por buena parte del catolicismo integral en Europa y algunos países de América Latina, tanto en dictaduras como en democracias más o menos consolidadas durante el periodo de entreguerras. 
de sus ocupaciones históricas: la evangelización de una sociedad que imaginaban «devastada" por el abandono de la religiosidad, un aspecto que vinculaban con las representaciones del anticlericalismo de la sociedad española de los años treinta. Al inicio de la dictadura, diferentes agentes revisaron sus estrategias de aproximación a los sectores trabajadores e inauguraron una nueva ola que marcaría un punto de inflexión -y de ruptura- con el catolicismo social anterior (Montero, 2000). El objetivo fue lograr la integración de las identidades alterizantes que no se habían aglutinado todavía bajo la estructura nacional de la Acción Católica en sociabilidades diferenciales atravesadas por una clasificación articulada en clave de edad, clase social y género. Con este propósito, vieron la luz los movimientos de especialización divididos por ambientes sociales: obrero, rural, y estudiantil, respectivamente.

Si bien la base de la especialización fue "selecta y relativamente minoritaria», en términos cuantitativos su actividad fue mucho más comprometida y destacada. Se trataba de sociabilidades menos elitistas, pero con una incidencia más exigente y comprometida en el plano social (Montero, 2005: 176). En este sentido, la participación de las identidades alterizantes en la Acción Católica se articuló precisamente desde la diferencia discursiva respecto de la militancia de clases más acomodadas de los círculos políticos, económicos y sociales. Su papel se contemplaba desde una entrega completa que atravesaba no solo la agencia de las identidades obreras femeninas en los mundos del trabajo asalariado, o su papel en el llamado apostolado obrero, sino que también condicionaba la rutina cotidiana de estas obreras católicas.

Tras charlar con algunos vecinos y vecinas de Béjar, el sacerdote de la JOCF se presentó en la casa de Lucía García, pues ya entonces la joven tenía cierta fama de "vocera» popular entre las trabajadoras del pueblo. De este modo sucedió el primer acercamiento de esta a unos métodos educativos diferentes de aquella religiosidad que había conocido en las monjas que atendían el comedor social de la tercera edad. Se trataba del método formativo de la Encuesta, el ver, juzgar y actuar procedente de la JOC belga. Este instrumento impulsaría a muchos trabajadores y trabajadoras a escribir de su puño y letra las primeras revisiones de vida donde reflexionaron profundamente sobre sus experiencias comunes y sobre las desigualdades sociales presentes en Béjar.

Si bien la joven trabajadora decidió participar en estos grupos jocistas de manera voluntaria y vehemente, antes de casarse y comenzar su andadura en la HOACF, Lucía recordaba que las «ricas» de Béjar, vinculadas al Movimiento de Mujeres de la Acción Católica, le pedían que convenciera a sus compañeras de trabajo para asistir a las actividades del círculo femenino de la parroquia. Una actividad que, a diferencia de las reuniones de la JOC, no pareciera entusiasmarle. En muchas ocasiones Lucía se enfrentó a ellas, a las 
«señoras», pues les recriminaba que aunque se acercasen de forma "amistosa» a las trabajadoras no entendían sus problemas cotidianos, la dureza de su trabajo en las fábricas, la experiencia de las familias obreras en la posguerra, y en particular, el desamparo de muchas jóvenes trabajadoras ante los poderes locales. Con enfado recordaba que la única preocupación de las católicas era que las trabajadoras se mantuvieran dentro de los códigos de honor y representaciones de moralidad nacional.

La hija del responsable de la fábrica donde trabajaba Lucía, vinculada a la Acción Católica, buscaba interpelar a las trabajadoras de La Estambrera en encuentros «fortuitos» que sucedían en las calles y plazas del pueblo. También solían acudir a las casas de las trabajadoras. En una ocasión, Lucía sermoneó a esta joven a propósito de la situación de gran parte de las trabajadoras de La Estambrera, las cuales debían caminar durante la noche por caminos sin iluminación hasta llegar a la fábrica, sufriendo asaltos y abusos en el camino. Algunas se hacían acompañar por sus padres o hermanos varones para evitar situaciones de violencia en la oscuridad de la noche ${ }^{11}$. Como recordaba Lucía, estas «mujeres de la moral», las católicas de las clases altas, eran "las hijas y mujeres de los jefes». La élite social católica que actuaba como base de apoyo del entramado franquista acabó instrumentalizando sus agentes para ejercer el control social en la localidad. La élite del empresariado textil, que detentaba el poder económico industrial del pueblo, contribuyó por su parte a la difusión en las prácticas empresariales de los valores del régimen franquista (Cohen \& Scull, 1983).

Se convertían así en representaciones reales de una catolicidad conservadora y seguidora de la moral integral, identidades aceptadas e incluidas bajo la construcción de la nueva identidad «nacional» del franquismo. Para la obrera, las relaciones sociales que se desarrollaban en Béjar obedecían a una estructura más propia del feudalismo que de la etapa moderna. A través del paternalismo, y también de la coerción amable que simbolizaban los «regalos» -ya fuera una ayuda económica, algún alimento para la familia o incluso sábanas para el ajuar matrimonial-, las dirigentes católicas se acercaban a las jóvenes con quienes tenían más confianza, para que fueran estas quienes convencieran a sus compañeras de fábrica para acudir a la iglesia. La feminidad católica como símbolo de identidad y ascenso social se concretaba en el fenómeno conocido como ma-

11. «Las chicas que venían de los pueblos, pues algunas las acompañaban los hermanos y los padres, se ganaban el jornal a medias. Tenían que salir a las tres o cuatro de la mañana para llegar a las cinco a la fábrica. Se trabajaban doce horas. Tenían que venir por los caminos de los pueblos a Béjar. Apareció una chica embarazada e inesperadamente el jefe la sancionó a ella. Nos daban los treinta duros al mes como prima y a ella se la quitaron por mala conducta. Se rumoreaba que, en la nave, abajo en los tejidos, el encargado general tenía una amante fija siempre y era de las aprendizas que iban entrando... era habitual que los contramaestres fueran a por las chavalas.» 
ternidad social. La extensión de los deberes maternales asociados a la construcción sociocultural de la categoría mujer para con la totalidad de la sociedad, otra forma de difundir las representaciones patrióticas en las identidades de los vencidos (Blasco, 2017: 271):

\begin{abstract}
«Después vienen las señoras de Acción Católica a pedirnos que las ayudemos a llevar a una catequesis de mujeres pobres, nuestra misión era animar a las más pobres a asistir. El primer día llego, veo yo aquello, las hablaban de catecismo y después las daban un pan.Y la siguiente vez una sábana. Consiguieron que el local se llenara y las llevaban a la iglesia» ${ }^{12}$.
\end{abstract}

Este aspecto nos muestra cómo la sociedad rural bejarana se encontraba fuertemente estratificada en términos de clase, y que mujeres de diferentes clases sociales rara vez se saludaban o incluso charlaban en los espacios comunes del pueblo. Así, las trabajadoras se encontraban más en sintonía dentro del movimiento jocista, donde existía una preocupación más orientada a la "elevación cultural», a la reflexión, y también hacia el desarrollo de una conciencia social desprovista de estas nociones históricas de caridad.

Por otro lado, no podemos subestimar la agencia de las mujeres de manera pasiva respecto de la movilización de las católicas. En numerosos casos, participaron de este intercambio piadoso por conveniencia, para tener un pedazo de pan que llevar a sus hogares o para acceder a bienes que de otra forma no hubieran podido adquirir por el alto precio en tiempos de posguerra ${ }^{13}$. En otras, la religiosidad aprehendida en sus familias, ligada también a ciertas tradiciones colectivas de la cultura popular, pudo tejer coincidencias en tanto esta catolicidad encontraba un espacio presente en la vida de las mujeres con anterioridad. Así, comprendemos el despliegue de una heterogeneidad de actitudes sociales ante la propaganda desarrollada por las católicas. Algunas de estas «mujeres pobres» comulgaban con la doctrina social de la Iglesia e incluso veían con buenos ojos esta ayuda o devoción de las clases altas. Otras, sin embargo, una vez hubieron recogido su pan o su juego de sábanas se apresuraban a criticar con sus vecinas «de clase» la opulencia de estas mujeres en sus propios lugares de recreo, incluso valiéndose del insulto, según el testimonio de Lucía.

\title{
12. Testimonio de Lucía García Hernández.
}

13. Lucía García recibirá con motivo del nacimiento de su primer hijo en 1958 un canasto de parte de una de las señoras de la Acción Católica de nombre Rufa Téllez. La trabajadora, ofendida al no compartir ya ciertos patrones de caridad de la asociación, lo devolvió no sin haberse enfrentado a su esposo y a su suegra, quienes le recordaron que la familia no podía permitirse disponer de uno. 
En este marco, en la agencia de las trabajadoras es necesario identificar una pluralidad de actitudes en la cotidianeidad, donde los intereses particulares y familiares también se conjugaron como un elemento clave. Por lo tanto, las trabajadoras no fueron sujetos pasivos a las que «se compró» con un mendrugo de pan, sino que la aceptación del juego del dar y recibir fue utilizado por algunas de ellas como estrategia de supervivencia. Ya en los espacios de sociabilidad propios, populares, donde las dirigentes católicas no escuchaban y las obreras se sentían más seguras, en comunidad, muchas manifestaron discretamente el poco interés que les despertaba participar de la práctica beata del catolicismo de posguerra:

«Les dije que si no les daba vergüenza comprar a la gente con un pan. Entonces las resultó como una ofensa espantosa. Según ellas aquellas mujeres las querían muchísimo.Yo ni corta ni perezosa les dije, mira, a ustedes por detrás las llaman zorras, y ellas le fueron diciendo al cura que yo les había llamado zorras. El cura se va a ver al obispo y le dice que yo soy comunista, que me excomulgue para quitar un peligro de la Iglesia... con 18 años. [...] Me excomulga. [...] Me llegó un papel que decía que se me prohibia terminantemente pertenecer a nada de la Iglesia. Me cogí una rabieta, rompí el papel y no quise saber más. Segui con los grupos de chicas [...] segui con los bailes regionales» ${ }^{14}$.

Si bien muchas mujeres del pueblo de Béjar charlaron en voz baja, entre chascarrillos, acerca de este parecer, incluso finjieron públicamente ciertas actitudes de negociación o acatamiento moral, la personalidad contestataria y transparente de Lucía, hicieron de ella una persona pública y conocida en el pueblo por su capacidad de interpelación. Por esta razón sería excomulgada por la jerarquía episcopal de Plasencia tras numerosos enfrentamientos con las católicas «ricas», a quienes increpó en varias ocasiones por tratar de «comprar» a las obreras durante estos años. Entendemos entonces que las mujeres no dejaron de manifestar su propia voz y agencia, incluso en ciertas comunidades rurales donde mantener posiciones de desacuerdo con los poderes locales podía traer consecuencias mucho más graves (Di Febo, 1979).

La contestación femenina al orden patriarcal del régimen nacionalcatólico suponía en cierta forma un destierro que, además, podía ser utilizado como instrumento de reproducción del miedo sobre otras personas. El castigo por desobeceder o alzar la propia voz emergía así como forma de señalamiento causado por actitudes contestatarias al interior de la Iglesia. Lucía García, antes de su participación en la JOCF y después en la HOACF,

14. Testimonio de Lucía García Hernández. 
ya manifestaba una impronta inconformista y activa que trataría de transmitir a las afiliadas de los movimientos del catolicismo obrero cuando se convirtió, a mediados de los cincuenta, en una de sus mayores referentes locales.

Por otro lado, es importante comprender que las señoras católicas partían de una identificación de clase cuando articularon discursos y consideraciones de género en el marco de un proyecto orientado a «reconquistar» por completo a la sociedad (Acha, 2000: 214). «Desde abajo» las trabajadoras se valieron estratégicamente de sus experiencias comunes para reivindicar una identidad obrera que también pudiera incorporar elementos de la religiosidad. Entre las mujeres de Béjar hubo unas pocas que identificaron las prácticas caritativas de la Acción Católica como método de presión para participar de una estructura de apoyo a la dictadura, aunque esta apreciación también puede interpretarse como una resignificación de la memoria y de los procesos históricos desde el tiempo presente (Llona, 2012b).

La cotidianeidad de las jóvenes trabajadoras bejaranas se vio alterada con una huelga de trabajo lento en La Estambrera en 1955 que duró cerca de un mes. En ella las obreras textiles pedían que se incorporase a más aprendizas y que se revisasen sus condiciones salariales. Entonces muchas trabajaban, entre ellas Lucía, a plus con el propósito de ahorrar algunas pesetas más y poder viajar con la JOCF a Roma.

La llegada al pueblo de Pepe Martín, otro sacerdote que había organizado el movimiento jocista en Plasencia, había dinamizado de nuevo cierta participación de las jóvenes de la industria textil en el asociacionismo católico. A su llegada a Béjar, el cura había acudido a visitar a Lucía García en su domicilio para pedirle que volviese a movilizar a sus compañeras de fábrica hacia la Iglesia. De nuevo los agentes católicos trataban de instrumentalizar a las personas que contaban con el reconocimiento en el interior de las comunidades obreras para tejer puentes con el sector trabajador de la población rural. Aunque la zurcidora se negó, el sacerdote intercedió con el obispo para lograr su readmisión en la Iglesia alegando precisamente la razón que había motivado su primera excomunión: evitar su caída en "el comunismo» ${ }^{15}$. Así fue como Lucía y otras jóvenes obreras pasaron a formar la incipiente JOCF en Béjar, y en 1957 viajaron a Italia para participar del Congreso de Roma. Aquí, las trabajadoras no solo disfrutarían de un itinerario turístico, sino

15. Los discursos del anticomunismo que condicionaron fuertemente las movilizaciones católicas durante las primeras décadas del siglo xx continuaban teniendo un peso destacado en las representaciones del franquismo, en especial en aquellas destinadas a señalar las identidades enemigas del régimen. Sinónimo de traición, amenaza o conspiración al orden autoritario, el franquismo se valió de la creación discursiva del anticomunismo como motor de intensificación del control social y de la represión sobre la población. 
que entrarían en contacto con integrantes jocistas de otras provincias de España, y también, con una parte del movimiento internacional, un aspecto que influenció enormemente la expansión de la JOCF en la siguiente década.

Tras contraer matrimonio con un jocista empleado de la industria textil en 1958, Lucía García abandonó su empleo en la fábrica. Ella manifestaba en sus memorias que no fue una decisión que tomó libremente. Efectivamente, la política legal del régimen y el peso del patriarcado familiar limitaban la continuidad de las mujeres en el mercado laboral. Según esta obrera textil estaba «mal visto» que las mujeres trabajasen en las fábricas una vez se casaban, de acuerdo con las representaciones de domesticidad que se difundían a través de los discursos y de las prácticas sociales bajo la España de Franco. Lucía apuntaba que, si una trabajadora se mantenía en su puesto de trabajo, daba a entender que su esposo tenía «menos capacidad» para mantener al núcleo familiar.

La participación de las mujeres en el mercado de trabajo podía quebrar la esencia de las masculinidades en tiempos del autoritarismo, en tanto sus representaciones estaban condicionadas por el rol de proveedor del hombre. Así, muchas mujeres como Lucía abandonaron durante esta etapa de posguerra sus empleos, un hecho que en ningún caso significó que dejasen de percibir un salario, ya que muchas continuaron vinculadas a la economía sumergida. Las trabajadoras no desaparecieron, sino que fueron forzadas a la invisibilidad. De este modo, ciertas reglamentaciones que contenían los convenios de trabajo, entre ellas, la dote, solo sirvieron para invisibilizar el trabajo extradoméstico de las mujeres, pero no lo erradicaron, en especial, en las familias obreras (Díaz Sánchez, 2007: 375). Lucía dejó de acudir físicamente a la fábrica, pero sus encargados le enviaban a su domicilio las piezas de tela que necesitaba para completar su trabajo de costura.

Tras dar a luz a su hijo mayor, la zurcidora comenzaría a formar parte de la HOACF. Lucía había escuchado hablar a Guillermo Rovirosa, el fundador de la HOAC masculina, durante uno de los viajes de este a Béjar. Durante los primeros años este movimiento funcionó "con tres o cuatro hombres del pueblo y un cura». El paso de la JOCF a la HOACF fallaba porque gran parte de sus miembros al contraer matrimonio contaban con menos tiempo para dedicar a las reuniones. También influía el talante o apertura de los sacerdotes ante los "problemas obreros", pues cuando se trataba de una figura excesivamente paternalista y conservadora, los trabajadores y las trabajadoras rápidamente comenzaban a ausentarse de las reuniones y los equipos se diluían en otras actividades cotidianas.

Los métodos de la HOACF, al igual que el ver, juzgar y actuar de la JOCF marcaron una impronta que diferenció pronto la religiosidad de las especializaciones obreras respecto de los movimientos generales de la Acción Católica. Durante este periodo, algunos 
consiliarios acudieron a Lucía García para que compartiera a los círculos de mujeres de la Acción Católica los métodos de formación que utilizaban en sus reuniones, algo que molestó a García, ya que por sus experiencias previas con las «señoras», las «ricas» del pueblo, sentía que «aquella gente» no iba a vivir «de verdad» el cristianismo como lo hacían los hombres de la HOAC y las mujeres de la HOACF. Más allá de esta sensación, Lucía García se valió de su subjetividad como trabajadora y de reivindicar su pertenencia de clase para recordar algunos códigos sociales que todavía funcionaban en Béjar durante la posguerra. De esta forma, ella explicaba que, durante este tiempo de posguerra, acudir a las casas de los ricos suponía "desclasarte a la fuerza».

La trabajadora justificaba este discurso argumentando que en Béjar las clases pudientes no hablaban directamente "con los pobres» de tú a tú cuando se cruzaban en la cotidianeidad de las calles y de las parroquias. De ahí su negativa a acudir a los "domicilios de las ricas» para enseñarles los métodos de la HOACF. Al igual que le había sucedido en otros enfrentamientos previos con las mujeres de la Iglesia católica, Lucía fue acusada de nuevo de "estar cerca del comunismo». Para estos actores y actrices del catolicismo social, manifestar una actitud de resistencia o desobediencia ante ciertas peticiones equivalía a asumir una ideología comunista y anticlerical y, por lo tanto, a ser señalado como identidad alterizante con creencias religiosas diferenciales que no eran validadas desde el poder.

Frente a estas acusaciones, Lucía García recordaba la importancia de la solidaridad que se gestaba entonces en el interior de la HOAC y de la HOACF. Por ejemplo, tras ser elegida representante de la $\mathrm{HOACF}$ en su diócesis, Lucía solía viajar habitualmente a otras provincias para impartir cursillos. Durante sus ausencias, sabía que contaba con la ayuda de su suegra y del resto de las militantes de la HOACF, muchas de ellas madres de familia. Estas quedaban también a cargo de sus hijos e hijas, repartiéndose las tareas de cuidado entre todas las mujeres y funcionando como una verdadera red de apoyo mutuo: "Cuando salían del colegio [se refiere a sus hijos e hijas menores] se iban a comer a casa de alguna amiga. A donde les pareciera. Pero tenían elegidas sus predilecciones».

Durante los primeros años de pertenencia a la HOACF, Lucía García solía escribir algunas octavillas que después repartía en el camino a las fábricas de los alrededores de Béjar durante la madrugada. Cuando los trabajadores y trabajadoras del primer turno salían se las encontraban en el camino de regreso a sus hogares. Utilizaba para esta tarea una máquina de escribir y una multicopista que había extraído de los locales de Acción Católica:

«Las primeras las hice yo, y las tiré, nadie sabía que tenía esa multicopista. Era porque en la fábrica donde trabajé todos los años se obligaba a los obreros a ha- 
cer ejercicios espirituales. Los tejedores que entraban a las cinco de la mañana tenían que estar a las ocho en el salón escuchando misa, y se quedaban dormidos [...] así no se inculcaba la fe a nadie, que entonces el que quisiera rezar que rezase, y que el jefe no era nadie para obligar.» ${ }^{16}$

Los recuerdos de Lucía nos permiten identificar dos dinámicas de la vida religiosa en el mundo rural. La primera, la connivencia o alianza del empresariado textil como base de apoyo al régimen. Esta identificación de los poderes económicos locales con los valores del régimen trajo consigo la intensificación de la vigilancia y el disciplinamiento de la mano de obra en los lugares de trabajo a través de ciertas prácticas, como la asistencia a los oficios o a los ejercicios espirituales. La segunda, que ya en los años cincuenta los círculos de influencia de la HOAC y de la HOACF marcaron distancia respecto de los códigos de ritualidad católica, del conservadurismo de la Acción Católica y del nacionalcatolicismo. Los trabajadores y trabajadoras identificados con el catolicismo en la comunidad de Béjar manifestaron una fuerte impronta de carácter social y, también, una capacidad de movilización que rechazaba de manera indirecta estas prácticas religiosas. Esta movilización de Lucía traería de nuevo consecuencias para la trabajadora, ya que fue denunciada por las Mujeres de la Acción Católica con la consiguiente visita policial para revisar su domicilio. En este caso, el hecho de conocer personalmente a los agentes, vecinos del pueblo, y de tratarles con cierta naturalidad tras atisbar su nerviosismo favoreció que estos no terminasen de completar el registro de la vivienda y que la multicopista no fuera descubierta. Pareciera que ciertas dinámicas de la vida rural y comunitaria de Béjar salvaron de nuevo a Lucía García de la posibilidad de ser juzgada por el franquismo.

\section{CONCLUSIONES}

Los recuerdos de Lucía García Hernández nos permiten no solo recontruir la historia de una identidad periférica en un contexto de ruralidad durante la posguerra, sino adentrarnos en el conocimiento de cómo funcionaba la cotidianeidad en un pueblo salmantino y conocer las bases sociales que se organizaron para apoyar o resistir al régimen franquista. Asimismo, nos permite analizar el funcionamiento de las instituciones de la Iglesia católica o las diferentes actitudes sociales que coexistieron en Béjar. Los relatos de la que fuera más adelante presidenta diocesana de la HOACF de Plasencia nos muestran no solo diferentes formas de resistencia, de aceptación o de coexistencia en una comunidad rural, sino que apuntan que, al contrario de lo que reflejan las fuentes católicas, para

16. Testimonio de Lucía García Hernández.

Historia Agraria, 85 - Diciembre 202I - pp. I8 $5^{-2 I I}$ 
las dirigentes no fue una labor sencilla ganarse a los sectores populares. Si bien se organizaron multitud de actividades propagandísticas en las parroquias durante la posguerra en Béjar, «las católicas» no tenían un acceso fácil a los lugares de trabajo de las obreras. Para ello, instrumentalizaron ciertas relaciones sociales con aquellas que consideraban en cierta forma representantes de los sectores subalternos para expandir su influencia moral más allá de los círculos de la élite industrial de Béjar, con la cual las identidades trabajadoras difícilmente podían identificarse.

Por otro lado, el carácter de Lucía García, contestatario, directo, le sirvió para ser blanco de las críticas de los sectores más conservadores de la Iglesia, pero al mismo tiempo, para convertirse en vocera de las trabajadoras ante los poderes religiosos y políticos de esta comunidad rural. Gracias a su movilización activa acudieron a ella buscando su favor tanto las trabajadoras como las señoras de las clases acomodadas y algunos sacerdotes. Si bien pareciera que Lucía hizo suyo el arte de la resistencia de una manera muy particular, a través de sus experiencias comprendemos también que no todas las obreras se atrevieron a manifestar su voz de esta manera y prefirieron utilizar otras estrategias más sutiles, como la negociación, el disimulo o incluso la actitud del fingir. Otras incluso esperaron a encontrarse en círculos de mayor intimidad y confianza para mostrar su desacuerdo con otras mujeres a través del desprecio. Por otro lado, en tiempos de la posguerra, algunas manifestaron comportamientos de cierta negociación con los sectores de la beneficencia y de la caridad de la Iglesia católica como estrategia de supervivencia contra el hambre.

En cualquier caso, estas valoraciones sobre las actividades piadosas estuvieron también en constante transformación, hilvanadas a su vez con el proceso de cambio que experimentan las identidades de las mujeres. Por ejemplo, Lucía García recordaba que durante su adolescencia veía en la caridad una forma de poder "mejorar» las condiciones materiales de las clases populares. Sería su paso por la JOC, unido a las duras experiencias que vivió y observó en la fábrica La Estambrera desde su adolescencia los hechos que determinaron fuertemente un cambio de conciencia en ella. Así, su idea de caridad fue sustituida por nociones de justicia del obrerismo católico y una fuerte identidad de clase. Ello distanció a Lucía de las representaciones del nacionalcatolicismo.

La influencia de su padre sería también un elemento clave en Lucía, ya que a través de la experiencia paterna ella comenzaría a marcar ciertos límites con la beneficencia católica. En este sentido, las redes de solidaridad tanto para Lucía como para su progenitor tuvieron mucho más peso que el clientelismo que todavía pervivía en Béjar. Estas experiencias comunes serían precisamente el elemento que garantizaría la cohesión de las identidades obreras "catolicas». Estas sociabilidades se convirtieron en una alternativa menos moralista para las trabajadoras, un lugar donde muchas pudieron encontrar un es- 
pacio de reflexión y de resignificación de sus identidades frente a la construcción del proyecto religioso y nacional de la Acción Católica como base de apoyo al régimen de Franco.

Finalmente, como han apuntado diversos autores y autoras, el desarrollo y difusión de la cultura de la victoria alcanzó una mayor proyección en contextos rurales como el de Béjar gracias a la agencia desplegada por ciertos sectores sociales vinculados a los poderes económicos, empresariales, a la élite política y a las instituciones locales de la Iglesia católica. Las religiosas encargadas de los comedores sociales, la actividad propagandística de las señoras y jóvenes de la Acción Católica, o la imposición de ciertas rutinas católicas en los lugares de trabajo por parte de los empresarios de la industria textil fueron solo algunas de las estrategias orientadas al disciplinamiento de esta comunidad rural asociada con ser foco de protesta durante las primeras décadas del siglo.

\section{AGRADECIMIENTOS}

Este artículo ha podido ser publicado gracias a la financiación del Consejo Nacional de Investigaciones Científicas y Técnicas de Argentina (CONICET) y también gracias a la labor de recuperación de las voces subalternas que ha desarrollado el Archivo de Historia del Trabajo-Fundación Primero de Mayo de Comisiones Obreras (CC.OO.). Agradezco de igual forma el detalle y precisión de las evaluaciones que recibió el artículo y que enriquecieron notablemente las perspectivas de análisis aquí reseñadas.

\section{REFERENCIAS}

ABAD, I. (2009). Las dimensiones de la «represión sexuada» durante la dictadura franquista. Revista de Historia ferónimo Zurita, (84), 65-86.

ACHA, O. (2000). Catolicismo social y feminidad en la década de 1930. En P. HALPERín \& O. ACHA (Comp.), Cuerpos, géneros e identidades: Estudios de historia de género en Argentina (pp. 195-227). Buenos Aires: Editorial del Signo.

ARCo, M. A. DEL (2006). Morir de hambre: Autarquía, escasez y enfermedad en la España del primer franquismo. Pasado y memoria: Revista de historia contemporánea, (5), 241-258.

ARCE, R. (2016). La construcción social de la mujer por el catolicismo y las derechas españolas en la época contemporánea. Tesis Doctoral. Santander: Universidad de Cantabria.

Arco, M. A. Del, Fuertes, C., Hernández Burgos, C. \& MArco, J. (Eds.) (2013). No sólo miedo: Actitudes políticas y opinión popular bajo la dictadura franquista (19361977). Granada: Comares. 
AsUnCión, A. DE LA (2017). El folclore como instrumento político: Los Coros y Danzas de la Sección Femenina. Revista Historia Autónoma, (10), 183-196.

BARrRenquero, E. \& Prieto, L. (2003). Asi sobrevivimos al hambre: Estrategias de supervivencia de las mujeres en la posguerra española. Málaga: Diputación Provincial de Málaga.

BJERG, M. (2019). Una genealogía de la historia de las emociones. Quinto Sol, (23), 1-23.

Blasco, I. (2005a). Dones i activisme catòlic: L'Acción Católica de la Mujer entre 1919 i 1950. Recerques: Història economía i cultura, (51), 115-139.

BLASCO, I. (2005b). «Sección Femenina» $\mathrm{y}$ «Acción Católica»: La movilización de las mujeres durante el franquismo. Gerónimo de Uztariz, (21), 55-66.

BLASCO, I. (2017). Religión, género y mujeres en la historia contemporánea: Balances y perspectivas. En F. MonTERO, J. DE LA Cueva \& J. LouZAO (Coords.), La historia religiosa de la España contemporánea: Balance y perspectivas (pp. 257-277). Alcalá de Henares: Universidad de Alcalá de Henares.

BRIONES, C. (1998). La alteridad del «Cuarto Mundo»: Una deconstrucción antropológica de la diferencia. Buenos Aires: Ediciones del Sol.

Cenarro, A. (2013). Los niños del Auxilio Social: Historia, memoria e identidades. Historia Social, (76), 145-163.

Cenarro, A. (2005). La sonrisa de Falange: Auxilio Social en la guerra civil y en la posguerra. Barcelona: Crítica.

CHARTIER, R. (1992). El mundo como representación: Estudios sobre historia cultural. Barcelona: Gedisa.

Cobo, F. \& ORTEGA, T. M. (2004). Hambre, desempleo y emigración: Las consecuencias sociales de la política agraria autárquica en Andalucía Oriental, 1939-1975. Hispania, 3 (218), 1079-1114.

Cobo, F. \& Ortega, T. M. (2005). Franquismo y posguerra en Andalucía Oriental: Represión, castigo a los vencidos y apoyos sociales al régimen franquista, 1936-1950. Granada: Universidad de Granada.

Cohen, S. \& Scull, A. (1983). Social Control and the State: Historical and Comparative Essays. Oxford: Blackwell.

DERRIDA, J. (1967). L'écriture et la différence. Paris: Éditions du Seuil.

Di Febo, G. (1979). Resistencia y movimiento de mujeres en España, 1936-1976. Barcelona: Icaria.

DíAz SÁncheZ, P. (2007). El trabajo en la confección-textil: Un oficio de mujeres. Espacio, Tiempo y Forma, Serie V, Historia Contemporánea, (19), 371-392.

Durkheim, E. (1987 [1893]). La división del trabajo social. Madrid: Akal.

GARAZI, D. (2016). Experiencia, leguaje e identidad: Algunas notas sobre el concepto de experiencia en la obra de Joan W. Scott. Trabajos y Comunicaciones, (43), e013. http://www.memoria.fahce.unlp.edu.ar/art_revistas/pr.7179/pr.7179.pdf 
GINZBURG, C. (1976). Il formaggio e $i$ vermi. Roma: Einaudi.

Gonzalbo, P. (2006). Introducción a la historia de la vida cotidiana. México, DF: Centro de Estudios Históricos/El Colegio de México.

Halbwachs, M. (2011 [1950]). La memoria colectiva. Buenos Aires: Miño y Dávila.

Hernández Burgos, C. (2011). Granada azul. La construcción de la «Cultura de laVictoria» en el primer franquismo. Granada: Comares.

Hernández Burgos, C. (2013). Misioneras de la patria: Las Mujeres de Acción Católica durante el primer franquismo (1936-1951). Actas del VII Encuentro Internacional de Investigadores del Franquismo. Barcelona: Universitat Autonoma de Barcelona/Fundación Cipriano García.

Hernández Burgos, C. (2014). Más allá del consenso y la oposición: Las actitudes de la "gente corriente» en regímenes dictatoriales: Una propuesta de análisis desde el régimen franquista. Revista de Estudios Sociales, (50), 87-100. http://journals. openedition.org/revestudsoc/8649

Hernández Burgos, C. (2019). Tiempo de experiencias el retorno de la «Alltagsgeschichte» y el estudio de las dictaduras de entreguerras, Ayer, (113), 303-317.

Hernández Burgos, C. \& Arco, M. A. Del (2011). Más allá de las tapias de los cementerios: La represión cultural y socioeconómica en la España franquista (19361951). Cuadernos de Historia Contemporánea, (33), 71-93.

Hobsbawm, E. (1999). Gente poco corriente: Resistencia, rebelión y jazz. Barcelona: Crítica.

LLONA, M. (2012a). Historia oral: La exploración de las identidades a través de las historias de vida. En M. Llona, Entreverse:Teoría y práctica de las fuentes orales (pp. 1560). Bilbao: Universidad del País Vasco.

Llona, M. (2012b). Entreverse: Teoría y práctica de las fuentes orales. Bilbao: Universidad del País Vasco.

Llona, M. (2016). E. P. Thompson: La formación de la clase obrera en Inglaterra, el feminismo y la Historia de género. En J. Sanz Hoya, J. Babiano \& F. Erice (EdS.), E. P. Thompson: Marxismo e historia social (pp. 153-176). Madrid: Siglo XXI.

López García, B. (1995). Aproximación a la historia de la HOAC: 1946-1981. Madrid: HOAC.

Lugones, M. (2008). Colonialidad y género. Tabula Rasa, (9), 73-101.

Marcilhacy, D. (2014). La Hispanidad bajo el franquismo. En S. Michonneau \& X. M. NúÑEZ SEIXAS (Eds.), Imaginarios y representaciones de España durante el franquismo (pp. 73-102). Madrid: Casa de Velázquez.

MARTÍN GutIÉRREZ, S. (2020). ¿Católicas con conciencia de clase?: Obreras y señoras de la Acción Católica Española en el franquismo: Una historia de influencias y desavenencias en torno al género, la religión y la clase. Pasado y Memoria. Revista de Historia Contemporánea, (20), 231-250. 
Miguel, R. \& Hobsbawm, E. (2013). La Historia desde abajo y el análisis de los agentes históricos. Rubrica Contemporanea, 2 (4), 1-22.

MinTz, S. (2008). Reflections on Age as a Category of Historical Analysis. Fournal of the History of Childhood and Youth, 1 (1), 114-23.

Molinero, C. (2003). La política social del régimen franquista: Una asignatura pendiente de la historiografía. Ayer, (50), 319-331.

Montero, F. (2000). La Acción Católica y el franquismo: Auge y crisis de la Acción Católica especializada en los años sesenta. Madrid: UNED.

Montero, F. (2005). Origen y evolución de la Acción Católica Española. En A. L. LóPez Villaverde, A. BotTi \& J. DE LA Cueva (Coords.), Clericalismo y asociacionismo católico en España, de la Restauración a la Transición: Un siglo entre el palio y el consiliario (pp. 133-159). Cuenca: Universidad Castilla-La Mancha.

Moreno, M. (2011). Mujeres, trabajadoras y católicas: La HOACF en el franquismo. En M. Ortiz Heras \& D. A. GonzÁlez (Coords.), De la cruzada al desenganche: La iglesia española entre el franquismo y la transición (pp. 133-159). Madrid: Sílex.

Moreno, M. (2016). Jóvenes trabajadoras cristianas: Compromiso social y aprendizaje ciudadano en la JOC. Ayer, (102), 95-119.

Murillo, I. (2012). En defensa de mi hogar y mi pan: Estrategias femeninas de resistencia civil y cotidiana en la Zaragoza de posguerra, 1936-1945. Zaragoza: Prensas de la Universidad de Zaragoza.

Nielfa, G. (Ed.) (2003). Mujeres y hombres en la España franquista: Sociedad, economía, política, cultura. Madrid: Instituto de Investigaciones Feministas/Universidad Complutense de Madrid.

ORTEGA, T. M. (2006). «Se hace camino al andar»: Balance historiográfico y nuevas propuestas de investigación sobre la dictadura franquista. Ayer, (63), 259-278.

PASSERINI, L. (2010). La memoria como subjetividad e intersubjetividad en las narraciones de memoria de las mujeres. En P. PÉREZ-Fuentes (Coord.), Subjetividad, cultura material y género: Diálogos con la historiografía italiana (pp. 115-131). Barcelona: Icaria.

PeInAdo, M. (2018). «Mujerucas» transgresoras: La «moralidad femenina» como herramienta condenatoria franquista. Historia y Comunicación Social, 23 (2), 339-353.

RocA, B. (2017). Pensar con James Scott: Dominación, conocimiento, resistencia. Araucaria. Revista Iberoamericana de Filosofía, Política y Humanidades, (37), 91-113.

Rodríguez Barreira, O. J. (2008). Migas con miedo: Prácticas de resistencia al primer franquismo: Almería, 1939-1953. Almería: Universidad de Almería.

Rosa, A., Bellelli, G. \& BAKHURST, D. (2008). Representaciones del pasado, cultura personal e identidad nacional. Educação e Pesquisa, 34 (1), 167-195.

ScotT, J. C. (1985). Weapons of the Weak: Everyday Forms of Peasant Resistance. New Haven:Yale University Press. 
Scott, J.W. (1989). Sobre el lenguaje, el género y la historia de la clase obrera. Historia Social, (4), 81-98.

SERnA, J. \& PONS, A. (2019). MicroHistoria: Las narraciones de Carlo Ginzburg. Granada: Comares.

Summerfield, P. (2004). Culture and Composure: Creating Narratives of the Gendered Self in Oral History Interviews. Cultural and Social History. The fournal of the Social History Society, 1 (1), 65-93.

Thompson, E. P. (1966). History from Below. The Times Literary Supplement, (65), 275280.

THOMPson, E. P. (1989 [1963]). La formación de la clase obrera en Inglaterra. Barcelona: Crítica. 